\title{
Immunization Laws and Policies Among U.S. Institutes of Higher Education
}

\author{
Journal OF LAW, MEDiCINe, AND ETHICS \\ Leila Barraza, J.D., M.P.H. \\ James G. Hodge, Jr., J.D., LL.M. \\ Chelsea L. Gulinson, J.D. \\ Drew Hensley \\ Michelle Castagne
}

Leila Barraza, J.D., M.P.H., is Assistant Professor, Mel and Enid Zuckerman College of Public Health, University of Arizona.

James G. Hodge, Jr., J.D., LL.M., is Professor of Public Health Law and Ethics; Director, Center for Public Health Law and Policy (CPHLP), Sandra Day O'Connor College of Law, Arizona State University (ASU).

Chelsea L. Gulinson, J.D., is Research Scholar, CPHLP, Sandra Day O’Connor College of Law, ASU.

Drew Hensley, J.D. Candidate (2020), is Senior Legal Researcher, CPHLP, Sandra Day O'Connor College of Law, ASU.

Michelle Castagne, J.D. Candidate (2021) is Legal Researcher, CPHLP, Sandra Day O’Connor College of Law, ASU. 
Considerable research on school vaccination laws and policies focuses on elementary, middle, and high school requirements. However, risks of infectious disease outbreaks are not limited to school-age children. Recent outbreaks of vaccine-preventable diseases (e.g., mumps and meningitis) among young adults at higher education institutions (e.g., university, college, and junior college campuses) have proliferated nationally. Collectively, they illustrate a pressing public health concern regarding low vaccination rates among higher education populations contributing to outbreaks of communicable diseases. A primary cause of these outbreaks are lax requirements for student vaccinations among higher education institutions as a requirement for matriculation.

A series of inconsistences and failures concerning vaccination law or policy requirements among select higher education institutions lends to profound public health and ethical repercussions for students and community members. Against the backdrop of rising rates or outbreaks of vaccine-preventable conditions among institutional populations, addressing these findings is vital to alleviate future outbreaks on campuses and surrounding locales.

\section{Institutional Vaccination Gaps and Communicable Disease Outbreaks}

Current vaccine-preventable disease outbreaks in primary education settings have caused several states to reconsider or abridge non-medical exemptions to their vaccination requirements for school-aged children. However, a growing gap in vaccination coverage also exists among higher education students. Divergent vaccine requirements among higher education institutions have led to the spread of largely eradicated communicable diseases. Select outbreaks of vaccinepreventable diseases at higher education institutions are illustrated in Figure 1. 


\section{Figure 1. Select Outbreaks of Vaccine-preventable Diseases Among Higher Education Institutions (2014-2019)}

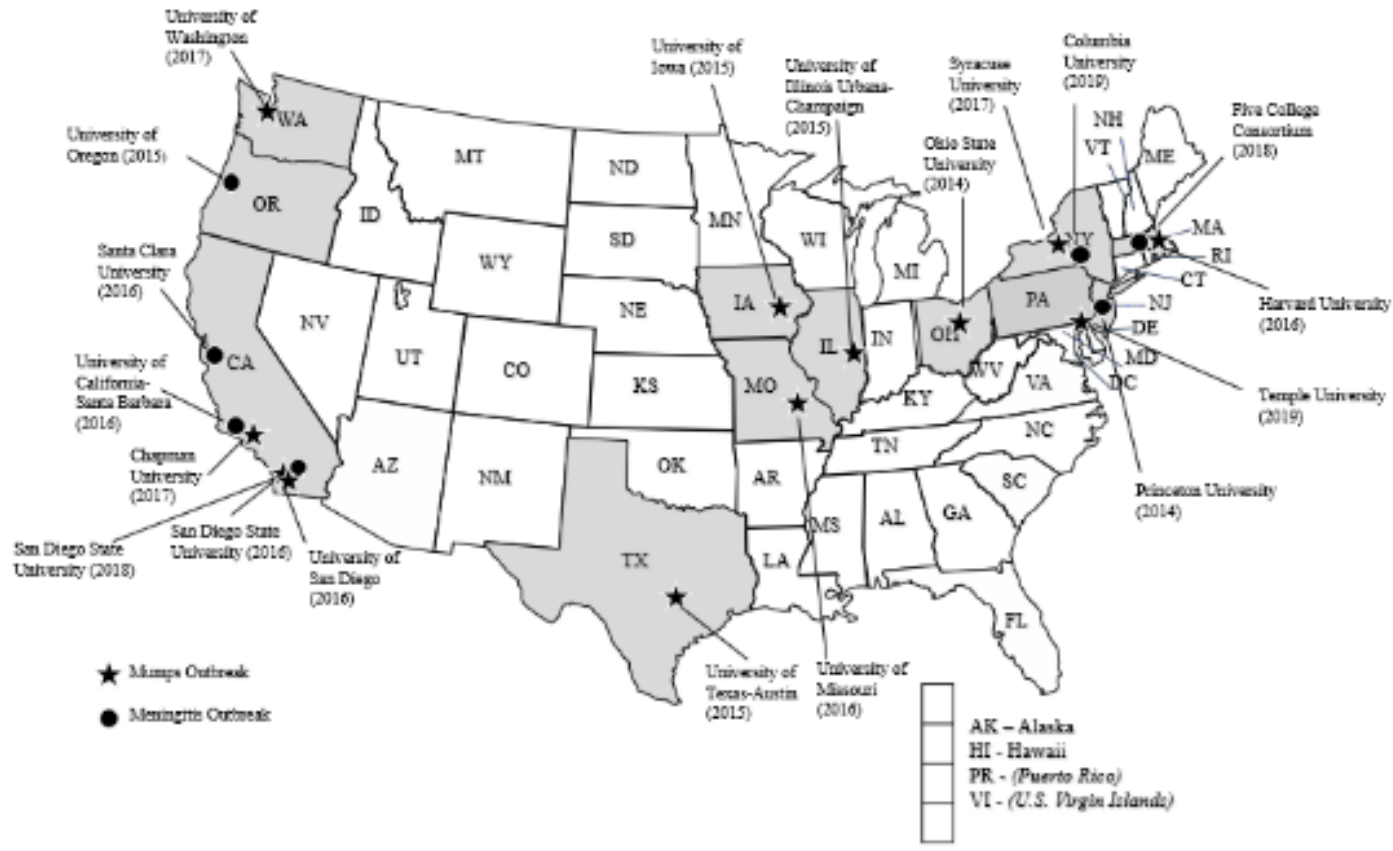

In late 2016, the Centers for Disease Control and Prevention (CDC) declared cases of mumps were at a 10-year high and triple the comparable number of cases from $2015 .{ }^{1}$ Between January 2016 and June 2017, there were 150 mumps outbreaks in the United States comprising 9,200 infections, half of which occurred in higher education campus settings. ${ }^{2}$ High-profile mumps outbreaks at the Universities of Missouri, Illinois at Urbana-Champaign, and Iowa, as well as Tufts and Harvard, garnered national attention. ${ }^{3}$ In response to the increased number of mumps outbreaks in the U.S. since 2015, CDC's Advisory Committee on Immunization Practices issued a recommendation that individuals at increased risk of mumps receive a third dose of the measles, mumps, rubella $(\mathrm{MMR})$ vaccine. ${ }^{4}$

States like California, Texas, and Washington have been hit the hardest by mumps outbreaks in higher education settings. In May 2015, the University of Texas-Austin reported an outbreak with 8 infected students, its first since the mumps vaccine was widely administered in 
1967. ${ }^{5}$ In 2016, San Diego State University (SDSU) and University of San Diego reported separate mumps outbreaks. ${ }^{6}$ SDSU offered free vaccinations to students for one week. ${ }^{7}$ In 2017, 12 students at Chapman University $(\mathrm{CA})^{8}$ contracted mumps; 75 students and staff received the MMR vaccine. ${ }^{9}$ At the University of Washington, 20 cases of mumps were reported that same year, mostly among fraternity and sorority students. ${ }^{10}$

Since 2012, outbreaks of meningitis have also emerged on higher education campuses, leading to at least one student's death at SDSU in 2014 and another at the University of Oregon in 2015. ${ }^{11}$ According to the National Meningitis Association, 5 higher education institutions experienced outbreaks of serogroup B meningococcal disease between 2013 and 2016 (Santa Clara University, University of Oregon, Providence College, Princeton University, University of California, Santa Barbara). ${ }^{12}$ These outbreaks prompted a proposal at the University of New Mexico to require all students to get vaccinated for meningitis. ${ }^{13}$ Arizona State University (among the nation's largest via student enrollment) strongly recommended (but did not require) meningitis vaccinations. ${ }^{14}$ Continued evidence of localized outbreaks among higher education campuses persists in $2019 .{ }^{15}$

\section{Assessment of Vaccine Requirements Across Higher Education Institutions}

A survey of vaccine laws and policies across select U.S. higher education institutions conducted by the Network for Public Health Law - Western Region Office revealed drastic inconsistencies. It identified public and private in-person, four-year institutions from all 50 states and the District of Columbia (D.C.), with the largest number of undergraduate enrollees (a minimum of 1,000 persons per institution). Data for 6 states (AK, MT, ND, NM, NV, WY) were derived solely from public institutions because no in-state private institutions met the enrollment requirement. 
A total of 8 vaccines were selected for survey review based on Immunization Recommendations for College Students published by the American College Health Association (ACHA). ${ }^{16}$ These vaccines include: MMR; tetravalent meningococcal conjugate (MCV4); Hepatitis B; Polio; Pneumonia; Varicella; Tetanus, Diphtheria, Pertussis (DTaP/Tdap/dT); and Human Papillomavirus (HPV). Additional vaccines (e.g., Hepatitis A, Influenza, and Meningitis Serogroup B) were noted in an "Other" category.

Survey results (see Figure 2) revealed extensive policy inconsistencies of vaccines required among matriculating students. Most institutions imposing at least one vaccine requirement allowed for exemptions based on medical necessity or religious, philosophical, or personal beliefs. Of the 96 total institutions assessed, 15 institutions required 5 vaccinations, the highest number of vaccinations required by any institution. Nine schools did not require proof of immunization for any vaccine-preventable disease, deferring instead on mere recommendations that students be vaccinated for an array of conditions. The MMR vaccine was most commonly addressed by higher education institution policies. Eighty-seven percent of institutions required students to receive the vaccine; another $8.3 \%$ recommended it. MCV4, DTaP, and Varicella vaccines were required among student populations $59.4 \%, 44.8 \%$, and $29.2 \%$ of the time, respectively. Polio, pneumonia, and HPV vaccines were recommended for students far more often than required.

Figure 2. Matriculation Immunization Requirements and Recommendations Among Select Higher Education Institutions 


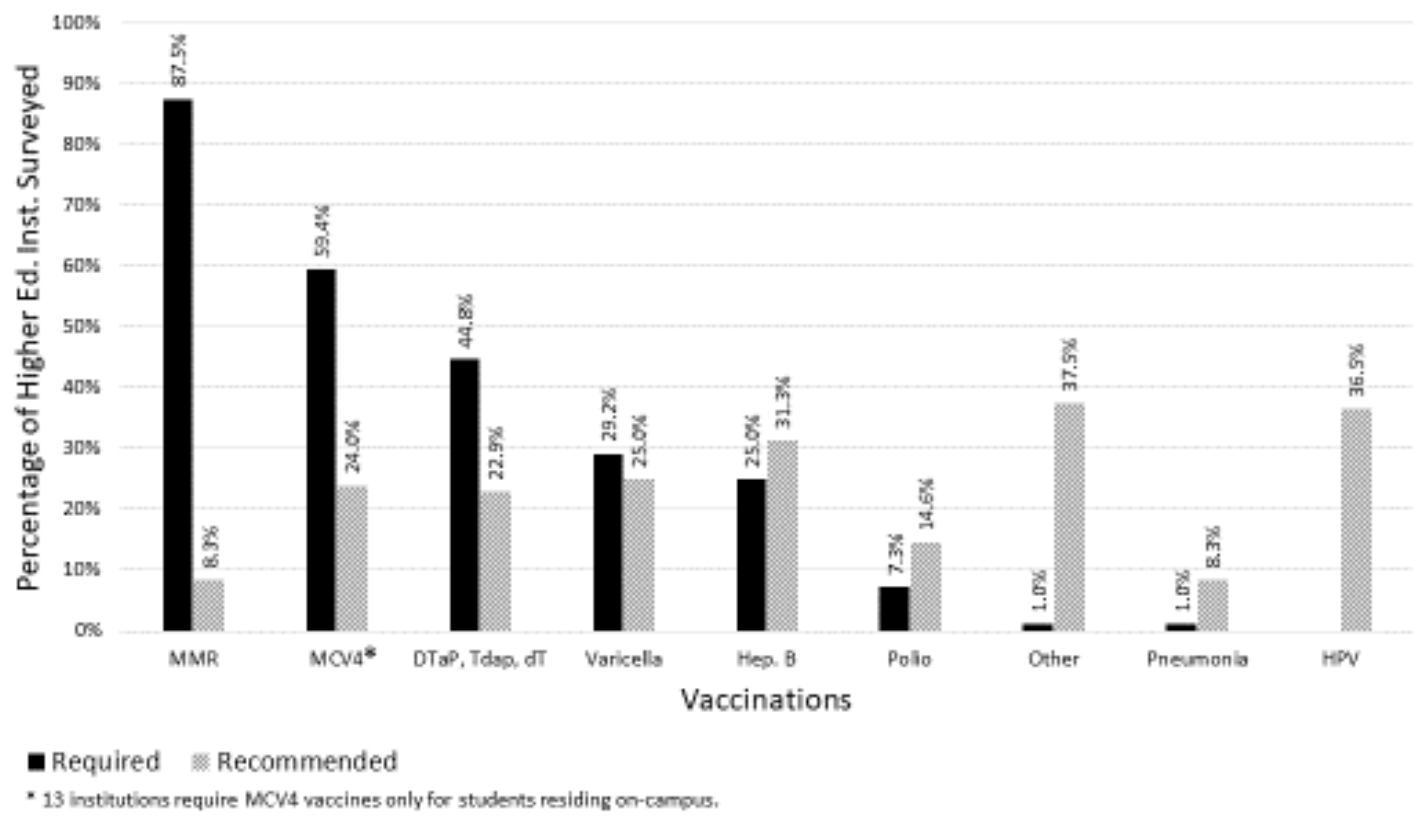

\section{Law and Policy Findings}

Only a few states feature specific laws governing vaccination requirements for higher education institutions. ${ }^{17}$ North Carolina, for example, requires proof of vaccination for 4 vaccines (MMR, DtaP/Tdap/dT, Hep. B, Polio) for all higher education students. Even when state law requires higher education vaccination, it often excludes an array of students (e.g., part-time students, students taking off-campus, evening, or weekend courses), which diminishes coverage and protection against certain vaccine-preventable diseases. ${ }^{18}$ Absent definitive or comprehensive state laws in many jurisdictions, higher education institutions develop vaccine policies that are often insufficient in scope. Only $70 \%$ of higher education institutions reviewed in the study required proof of more than one vaccine as a component of their matriculation policy.

Some states set specific vaccine requirements for higher education institutions following an outbreak. After a mumps outbreak at Harvard University, Massachusetts required MMR, DTaP, meningitis, varicella, and polio vaccines for higher education students. ${ }^{19}$ Though purposeful, these reactive laws vary significantly from lower-level school mandates, contributing to potential 
disease spread. In 2014, for example, Arkansas' legislature reformed its state laws to require proof of vaccination for only measles, mumps, and rubella for higher education students,$^{20}$ even though elementary school children in the state must be vaccinated for 12 diseases. ${ }^{21}$ State law in Colorado only requires higher education students to prove their immunity to meningitis. ${ }^{22}$

Exemptions and matriculation timing exceptions also contribute to the spread of vaccinepreventable diseases. Vaccination requirements at higher education institutions often include exemptions for medical, non-medical, religious, reasons of conscience, personal, and philosophical reasons. At many universities, obtaining an exemption is easier than submitting proof of vaccination, allowing for passive anti-vaccination that exposes communities to disease. Additionally, at the University of Illinois Urbana-Champaign, ${ }^{23}$ students may attend first semester classes before submitting proof of vaccination. Virginia, with arguably one of the most comprehensive higher education vaccination laws in the country, does not require student proof of immunization until second semester or quarter registration. ${ }^{24}$ As a result, unvaccinated students can live on campus without proper documentation for nearly six months, risking the health of students, faculty, and the surrounding community.

\section{Ethical Repercussions}

A solution to weak and inconsistent vaccine laws and policies among higher education institutions is to ramp up such requirements uniformly across the country. It is not that easy, however. Proposed vaccination requirements for higher education settings must balance individual rights with public health and safety interests. Pervasive ethical issues include student and faculty autonomy, respect for religious or personal exemptions, health information privacy, and enforcement of vaccine requirements. 
Most populations on higher education campuses are autonomous adults fully capable of making informed decisions about immunization practices. However, some are minors or "quasiadults," (i.e., legal adults garnering health insurance benefits or other influence among their parents or guardians), who might not make fully autonomous decisions regarding their health care. Legitimate medical exemptions from vaccines are ethically- and constitutionally-sound. No one who is an unfit medical candidate for a vaccine should be required to receive one irrespective of the setting. However, religious or philosophical objectors may find their interests do "not include liberty to expose the community ... to communicable disease. ${ }^{25}$ In essence, their interests may be balanced ethically against the welfare of the community. Principles of public health ethics sustain imposition of efficacious vaccine requirements among even autonomous adults in specific settings, such as institutional campuses, where the risks of exposure and infection are heightened.

\section{An Action Agenda}

Higher education institutions set on creating safe and healthy learning environments for students, faculty, staff, and their surrounding communities disallow the possession or use on campus of guns and other weapons, tobacco products, illicit drugs, alcohol, and other threats. They raise awareness on risks of sexual assault, prohibit hate-based acts, and limit dangerous activities. Yet, somehow, as our survey suggests, they either directly allow, or do not aggressively prevent, unvaccinated students to assemble and risk the health of populations. This is untenable.

Critical findings from this survey support key changes in laws and policies across the U.S. related to higher education vaccination requirements for student populations. At a minimum, state and local lawmakers and higher education boards and leaders must consider the actual risks of high rates of unvaccinated students leading to preventable outbreaks on and off campuses. 
Escalations in the rates and intensities of these outbreaks nationally support consideration of affirmative vaccine requirements for students matriculating at these institutions.

As in elementary and secondary schools, requiring greater rates of vaccination is key to prevention. From a public health perspective, forsaking enhanced vaccination compliance is nearly indefensible. Abject failures to address higher education rates of vaccination may even raise claims of liability, especially on private campuses which do not enjoy some level of governmental immunity applicable to public universities.

Higher education institutions that can demonstrate sufficiently high rates of vaccinations among their student bodies in a given year can circumvent the onset and negative repercussions of on-campus disease outbreaks. However, routine compliance with vaccinations may be assured consistently when underwritten by state, local, or institutional vaccine requirements. Exceptions to such requirements, notably concerning unfit candidates, are legally viable. Curbing easy access to religious, philosophical, or conscience-based objections to vaccinations that undermine herd immunity is essential.

Law and policy are proven, powerful tools to increase vaccination rates. Absent affirmative state laws, higher education institutions have devised vaccine policies that are substandard among many institutions, and non-existent among a few. Overly-generous exemptions and matriculation timing exceptions escalate the possibility of disease spread. While underlying ethical issues pose challenges to mandatory vaccine requirements, these challenges fail to outweigh the need to protect students and communities from risk of disease. Higher education institutions must develop comprehensive vaccine requirements to lower rates of vaccine-preventable diseases and related outbreaks on campuses across the U.S. 


\footnotetext{
${ }^{1}$ Mary Marcus, "Mumps cases at a 10-year high, colleges hard hit," CBS News, December 12, 2016, available at

$<$ http://www.cbsnews.com/news/mumps-cases-10-year-high-college-outbreaks-vaccination/> (last visited March 12, 2019).

${ }^{2}$ Susan Scutini, "CDC recommends booster shot of MMR vaccine during mumps outbreaks," CNN, October 25, 2017, available at $<$ https://www.cnn.com/2017/10/25/health/cdc-mumps-outbreak-syracuseuniversity/index.html> (last visited March 12, 2019).

${ }^{3}$ Rebecca Smith, "Mumps cases balloon in 2016, raising debate about need for booster vaccines," $P B S$, December 26, 2016, available at <http://www.pbs.org/newshour/rundown/mumps-cases-spike-2016raising-questions-need-booster-vaccines/> (lasted visited March 12, 2019).

${ }^{4}$ M. Marin et al., "Recommendation of the Advisory Committee on Immunization Practices for Use of a Third Dose of Mumps Virus-Containing Vaccine in Persons at Increased Risk for Mumps During an Outbreak," January 12, 2018, available at $<\mathrm{https}: / / \mathrm{www} . c d c . g o v / \mathrm{mmwr} / \mathrm{volumes} / 67 / \mathrm{wr} / \mathrm{mm} 6701 \mathrm{a} 7 . \mathrm{htm}>$ (last visited March 12, 2019).

${ }^{5}$ Andy Jechow, "UT student diagnosed with mumps, vaccine encouraged," $K X A N$, January 27, 2016, available at $<$ http://kxan.com/2016/01/27/ut-student-diagnosed-with-mumps-campus-notified/> (last visited March 12, 2019).

${ }^{6}$ Paul Sisson, "Five mumps cases at USD," San Diego Union Tribune, March 14, 2016, available at $<$ http://www.sandiegouniontribune.com/news/health/sdut-usd-mumps-outbreak-five-2016mar14story.html> (last visited March 12, 2019).

${ }^{7}$ Natasha Mascarenhas, "What you need to know about the mumps outbreak on college campuses," USA TODAY, December 13, 2016, available at <http://college.usatoday.com/2016/12/13/what-you-need-toknow-about-the-mumps-outbreak-on-college-campuses/> (last visited March 12, 2019).

${ }^{8}$ Courtney Perkes, "Chapman University mumps cases increase to 12," Orange County Register, April 12, 2017, available at $<$ https://www.ocregister.com/2017/04/12/chapman-university-mumps-casesincrease-to-12/> (last visited March 12, 2019).

${ }^{9}$ Courtney Perkes, "Chapman students get vaccinated to quell mumps outbreak on campus," Orange County Register, April 5, 2017, available at <http:/www.ocregister.com/2017/04/05/chapman-studentsget-vaccinated-to-quell-mumps-outbreak-on-campus/> (last visited March 12, 2019).

${ }^{10}$ Bob Young, "Mumps outbreak spreads to UW Greek system," Seattle Times, March 23, 2017, available at $<\mathrm{http}$ //www.seattletimes.com/seattle-news/health/mumps-outbreak-spreads-to-uw-greeksystem/> (last visited March 12, 2019).

${ }^{11}$ National Foundation for Infectious Diseases, Meningococcal Serogroup B Cases and Outbreaks on US College Campuses, available at $<\mathrm{http}$ :/www.adolescentvaccination.org/vpd/meningitis/meningococcal-bcollege-outbreaks.html $>$ (last visited March 12, 2019).

${ }^{12}$ National Meningitis Association, Serogroup B Meningococcal Disease Outbreaks on U.S. College Campuses, available at $<$ https://www.nmaus.org/disease-prevention-information/serogroup-bmeningococcal-disease/outbreaks> (last visited March 12, 2019).

${ }^{13}$ Jennie Ngyen, "UNM students may be required to get meningitis vaccination," KRQE, October 28, 2016, available at $<\mathrm{http}: / / \mathrm{krqe} . \mathrm{com} / 2016 / 10 / 28 / \mathrm{unm}$-students-may-be-required-to-get-meningitisvaccination/> (last visited March 12, 2019).

${ }^{14}$ ASU Health Services, Health Updates, available at https://eoss.asu.edu/health/resources/healthupdates (last visited March 12, 2019).

${ }^{15}$ Centers for Disease Control and Prevention, Meningococcal Outbreaks, March 28, 2017, available at $<$ https://www.cdc.gov/meningococcal/outbreaks/index.html $>$ (last visited March 12, 2019).

${ }^{16}$ American College Health Association, Immunization Recommendations for College Students, October 2018, available at $<\mathrm{https} / / \mathrm{www}$.acha.org/documents/resources/guidelines/ACHA_Immunization_

Recommendations_Oct2018.pdf> (last visited March 12, 2019).
} 
${ }^{17}$ National Vaccine Information Center, State Law \& Vaccine Requirements, available at $<$ https://www.nvic.org/Vaccine-Laws/state-vaccine-requirements.aspx > (last visited March 13, 2019). ${ }^{18}$ North Carolina Department of Health and Human Services, Colleges and Universities, February 27, 2018, available at $<\mathrm{https} / / \mathrm{www}$.immunize.nc.gov/schools/collegesuniversities.htm\#dtap $>$ (last visited March 12, 2019).

${ }^{19}$ Letter from Pejman Talebian, MA, MPH, Director Immunization Program to College Health Service Directors (Sept. 2017).

${ }^{20}$ A.C.A. § 6-18-702.

${ }^{21}$ Arkansas State Board of Health, Rules and Regulations Pertaining to Immunization Requirements, September 1, 2014, available at $<$ https:/www.healthy.arkansas.gov/images/uploads/rules/Immunization Requirements.pdf $>$ (last visited March 12, 2019).

${ }^{22}$ C.R.S. 23-5-128.

${ }^{23} \mathrm{McKinley}$ Health Center, Immunization Information, available at $<\mathrm{https}$ ://mckinley.illinois.edu/newstudents/immunization-information> (last visited March 12, 2019).

${ }^{24}$ Virginia Code $\S 23.1-800$ (2018).

${ }^{25}$ Prince v. Massachusetts, 321 U.S. 158, 166 (1944). 